\title{
Article \\ Hydroxyapatite and Silicon-Modified Hydroxyapatite as Drug Carriers for 4-Aminopyridine
}

\author{
Laura Marincaș ${ }^{1}$ (D) Graziella Liana Turdean ${ }^{1}$, Monica Toșa ${ }^{2}$, Zsolt Kovács ${ }^{3}$, Béla Kovács ${ }^{3}$ (D) Réka Barabás ${ }^{4, *}$, \\ Noémi-Izabella Farkas ${ }^{5, *}$ and Liliana Bizo ${ }^{5}$
}

1 Department of Chemistry, Faculty of Chemistry and Chemical Engineering, Babeș-Bolyai University, 11 Arany János Street, 400028 Cluj-Napoca, Romania; laura.marincas@ubbcluj.ro (L.M.); graziella.turdean@ubbcluj.ro (G.L.T.)

2 Enzymology and Applied Biocatalysis Research Centre, Faculty of Chemistry and Chemical Engineering, Babeş-Bolyai University, 11 Arany János Street, 400028 Cluj-Napoca, Romania; monica.tosa@ubbcluj.ro

3 Department of Biochemistry and Environmental Chemistry, Faculty of Pharmacy, George Emil Palade University of Medicine, Pharmacy, Science, and Technology of Târgu Mures, Gheorghe Marinescu 38 Street, 540142 Târgu Mureș, Romania; zsolt.kovacs@umfst.ro (Z.K.); bela.kovacs@umfst.ro (B.K.)

4 Department of Chemistry and Chemical Engineering of Hungarian Line of Study, Faculty of Chemistry and Chemical Engineering, Babeș-Bolyai University, 11 Arany János Street, 400028 Cluj-Napoca, Romania

5 Department of Chemical Engineering, Faculty of Chemistry and Chemical Engineering, Babes-Bolyai University, 11 Arany János Street, 400028 Cluj-Napoca, Romania; liliana.bizo@ubbcluj.ro

* Correspondence: reka.barabas@ubbcluj.ro (R.B.); noemi.farkas@ubbcluj.ro (N.-I.F.)

Citation: Marincas, L.; Turdean, G.L.; Toșa, M.; Kovács, Z.; Kovács, B.; Barabás, R.; Farkas, N.-I.; Bizo, L. Hydroxyapatite and Silicon-Modified Hydroxyapatite as Drug Carriers for 4-Aminopyridine. Crystals 2021, 11, 1124. https://doi.org/10.3390/ cryst11091124

Academic Editor: Witold Łojkowski

Received: 8 August 2021

Accepted: 11 September 2021

Published: 15 September 2021

Publisher's Note: MDPI stays neutral with regard to jurisdictional claims in published maps and institutional affiliations.

Copyright: (c) 2021 by the authors. Licensee MDPI, Basel, Switzerland. This article is an open access article distributed under the terms and conditions of the Creative Commons Attribution (CC BY) license (https:// creativecommons.org/licenses/by/ $4.0 /)$.
Abstract: Adsorption and desorption properties of nano-hydroxyapatite (HAP) and silicon-modified hydroxyapatite (Si-HAP) were investigated with 4 -aminopyridine (fampridine-4AP). The novelty of this research is the investigation of the suitability of the previously mentioned carriers for drugdelivery of 4AP. UV-VIS spectrophotometric results showed that the presence of silicon in the carrier did not significantly affect its adsorption capacity. The success of the adsorption was confirmed by thermal analysis (TG/DTA), scanning electron microscopy (SEM)/energy dispersive X-ray (EDX), Fourier transform infrared (FTIR) spectroscopy, and X-ray powder diffraction (XRPD). Drug release experiments, performed in simulated body fluid (SBF), revealed a drug release from Si-HAP that was five times slower than HAP, explained by the good chemical bonding between the silanol groups of the carrier and the 4AP functional groups. The electrochemical measurements showed a value of the polarization resistance of the charge transfer $\left(R_{\mathrm{ct}}\right)$ more than five times smaller in the case of $\mathrm{Si}-\mathrm{HAP}$ coating loaded with $4 \mathrm{AP}$, so the charge transfer process was hindered. The electrochemical impedance results revealed that electron transfer was inhibited in the presence of $4 \mathrm{AP}$, in concordance with the previously mentioned strong bonds. The silicon substitution in HAP leads to good chemical bonding with the drug and a slow release, respectively.

Keywords: 4-aminopyridine; hydroxyapatite; drug adsorption; electrochemistry

\section{Introduction}

Various drugs can be easily introduced into the human body using nanotechnology and nanomaterials. The real effects of nanotechnologies in the field of human medicine remain limited, as many of the key properties of these materials remain unknown [1]. However, the closer we get to the knowledge of diseases at the molecular level, the easier it will be to apply nanotechnologies in the future. Hydroxyapatite (HAP) is one of the few nanomaterials that are able to deliver drugs to the body without interfering with physiological processes [2].

HAP is a calcium phosphate with a high specific surface area, low water solubility, corrosion resistance and ion exchange capacity. HAP has mainly been used in dentistry 
and implantology [3-6], but at the same time as the development of nano-HAP, its study as a drug carrier $[7,8]$ has come to the forefront of research.

In our previous researches, we already investigated the sorption properties of HAP and various HAP-based composites with different adsorbates [9-13]. The additives, structural modifications and the adsorption efficiency were greatly influenced by the nature of the adsorbent. Synthetic and natural active substances showed different release profiles of the same carrier [9]. Functionalized coated HAP nanoparticles were used by others for sustained release of amoxicillin which was confirmed on animal experiments and was assigned to the antibacterial and bioactive properties of the used nanostructures [14].

Generally, the presence of the appropriate amount of silica in the HAP structure increases the adsorption efficiency $[11,15]$ because of the increased possibility of interactions with specific molecules [16]. Many researchers have conducted significant efforts to study the synthesis of silicon-substituted hydroxyapatite, with the result indicating that $\mathrm{SiO}_{4}{ }^{4-}$ ion substituted $\mathrm{PO}_{4}{ }^{3-}$ group site in apatite structure $[17,18]$. Mostafa et al. showed that silicate substitution was dominated by two charge compensation mechanisms acting simultaneously: firstly, $\mathrm{SiO}_{4}{ }^{4-}$ and $\mathrm{CO}_{3}{ }^{2-}$ groups were substituted for two $\mathrm{PO}_{4}{ }^{3-}$ groups, and secondly, the $\mathrm{SiO}_{4}{ }^{4-}$ group was substituted for one $\mathrm{PO}_{4}{ }^{3-}$ group, and a vacancy was formed in the $\mathrm{OH}$ - site. Moreover, the imperfections introduced by silicon substitution may play an important role in enhancing bioactivity [18]. Although studies on the drugbinding properties of silica-modified hydroxyapatite (Si-HAP) composites are incomplete in the literature, the mesoporous silica and mesoporous silica-HAP composites are a highly researched field because of their excellent adsorption capacity. Particle structure, pore size, and pore length also play important roles in the drug binding process [19]. Research with ibuprofen (IBU) has shown that hydrogen bonds between silanol (Si-O-H) groups and carboxyl $(-\mathrm{COOH})$ or hydroxyl $(-\mathrm{OH})$ groups of IBU play a significant role in the process [16]. Similarly, in the case of mesoporous silica-HAP composites, the mesoporous silica can also be attributed to the electrostatic bonds formed between $\mathrm{Ca}^{2+}$ cations and the carboxyl group of the IBU molecule [20].

The decrease of the released amount of a drug depends on the drug-HAP interaction between the groups [21] and on the pore length of the carrier material [17]. Rafaela C. R. dos Apostolos et al. prepared mesoporous silica-HAP composites containing methacrylic acid and copper, which are suitable for the incorporation and regular release of methotrexate (anticancer drug) [22]. Due to the forming interactions, the release kinetics of atenolol from HAPcontaining composites was optimal and the effect of the pore size was less significant [23].

As can be seen from the above, in addition to the use of HAP and HAP composites as drug carriers for antibacterial and anti-inflammatory agents, it is also suitable for the binding of other diseases' active substances.

Fampridine (4AP), chemically known as 4-aminopyridine, is currently the only pharmaceutical ingredient that is approved by the major regulatory bodies (U.S. Food and Drug Administration-FDA, European Medicines Agency-EMA) for the improvement of walking in patients with multiple sclerosis (MS) [24]. Nowadays, more than 2 million people suffer from MS, which is the most common cause of disability in the juvenile population [25]. Fampridine is available as $10 \mathrm{mg}$ prolonged-release film-coated tablets, in the form of an HPMC matrix formulation, with a general posology schedule of two times per day [26]. The active substance is freely soluble in water and purified, being classified as a class I substance according to the Biopharmaceutical Classification System, meaning that its permeability is complete at the site of administration [27]. Its mechanism of action lies in its potential to block the voltage-dependent potassium channels (Kv1), contributing to the improvement of the action potential propagation in demyelinated axons [28,29]. The extensive literature survey concerning the analytical methods that have been developed so far for the analysis of 4AP implies the use of HPLC methods [30-34], LC-MS techniques [35-37], as well as simple UV-spectroscopic determinations [38,39]. A reference method for the in vitro release kinetics of the active substance has been disclosed by the FDA, which uses the paddle 
method, at $50 \mathrm{rpm}$, in $900 \mathrm{~mL}$ phosphate buffer solution at $\mathrm{pH}=6.8$, with specific sampling time points of $0.5,1,2,4,6,8,10$, and $12 \mathrm{~h}$ [40].

Nowadays, the study of the adsorption of 4AP on bio-carriers is a less common research theme. Quantum chemical calculations (DFT) showed that 4AP was able to bind covalently through nitrogen with fullerene-like nanostructures. Secondary interaction could occur between the potassium atom of the "cage" and the hydrogen atom of the 4AP amine group [41]. Empirical experiments investigated the adsorption of 4AP on loughlinite $\left(\mathrm{Na}_{2} \mathrm{Mg}_{3} \mathrm{Si}_{6} \mathrm{O}_{16} \cdot 8 \mathrm{H}_{2} \mathrm{O}\right)$ using infrared spectrophotometry. It was demonstrated that the surface silanol groups played an important role in the adsorption process [42].

HAP and its modified composites are mainly studied in the literature for use in implantology. These biomaterials have proven to be successful drug carriers for both anti-inflammatory and antibiotic drugs. The aim of the present study was to investigate the before-mentioned bioceramics, with biocompatibility and excellent adsorption properties, as drug carriers for fampridine. This study is of primary importance as the proper functioning of the immune system is very important in patients with multiple sclerosis. HAP can be an excellent drug carrier, even in patients with such a disease, as it elicits a minimal immune response in the human body through its biocompatibility [43-46].

\section{Materials and Methods}

Calcium nitrate tetrahydrate $\left(\mathrm{Ca}\left(\mathrm{NO}_{3}\right)_{2} \cdot 4 \mathrm{H}_{2} \mathrm{O}\right.$, purity $\left.\geq 99 \%\right)$, diammonium hydrogen phosphate $\left(\left(\mathrm{NH}_{4}\right)_{2} \mathrm{HPO}_{4}\right.$, purity $\left.\geq 98.0 \%\right)$, sodium silicate $\left(\mathrm{Na}_{2} \mathrm{SiO}_{3} \cdot 5 \mathrm{H}_{2} \mathrm{O}\right)$ and ammonia solution (25\%) were purchased from Carl Roth GmbH (Germany) and were used as starting materials for the preparation of HAP and Si-HAP. Fampridine was obtained from Procos S.p.A. (Cameri, Italy).

The salts used to prepare simulated body fluid (SBF), and the electron transfer agents for electrochemical measurements $\left(\mathrm{K}_{3}[\mathrm{Fe}(\mathrm{CN})]_{6} / \mathrm{K}_{4}[\mathrm{Fe}(\mathrm{CN})]_{6}\right)$, were supplied from Sigma Aldrich (Burlington, MA, USA). The chitosan solution was obtained by dissolving $10 \mathrm{mg}$ chitosan (Sigma Aldrich, from crab shells) to $10 \mathrm{~mL}$ of $0.1 \mathrm{M}$ acetic acid, followed by a sonication step, for $30 \mathrm{~min}$.

All reagents were of analytical degree and were used without further purification. Distilled water was used for preparing aqueous solutions of different concentrations by dissolving the appropriate weights of salts.

\subsection{Characterization}

A Jasco V-650 UV-VIS double-beam spectrophotometer (Tokyo, Japan) was used for adsorption (in the liquid phase) and desorption measurements. Fourier transform infrared (FTIR) measurements were performed using a Bruker VECTOR 22 spectrophotometer (Reston, VA, USA). The samples were measured in the solid phase using KBr pellets. In order to investigate the crystallinity of the prepared materials, powder X-ray diffraction (XRPD) was carried out with a Bruker D8 Advance diffractometer (Berlin, Germany), using $\mathrm{CuK} \alpha$ radiation at $40 \mathrm{KV}, 40 \mathrm{~mA}$, and $\lambda=1.54060 \AA$.

Scanning electron microscopy (SEM) images were obtained with a CFEG SEM Hitachi SU8230 microscope (Japan) connected to an AZtec 80 X-Max Oxford Instruments EDX detector (Oxford, UK).

Thermogravimetry (TG) and differential thermal analysis (DTA) investigations of the samples were measured with TA Instruments SDT Q600 equipment (New Castle, DE, USA), under nitrogen atmosphere between $30^{\circ} \mathrm{C}$ and $1000^{\circ} \mathrm{C}$, at a heating rate of $10 \% / \mathrm{min}$. The amount of $4 \mathrm{AP}$ bound to the carriers' surface and the amount of $4 \mathrm{AP}$ in the pores were calculated by the following equations [47]:

$$
\begin{aligned}
l_{4 A P, s} & =\frac{\left[W_{c l s}-W_{c}\right]_{30-225}}{m_{c}} \\
l_{4 A P, p} & =\frac{\left[W_{c l s}-W_{c}\right]_{225-1000}}{m_{c}}
\end{aligned}
$$


where $l_{4 A P, s}$ - the amount of $4 \mathrm{AP}$ bound to the surface ( $\mathrm{g} 4 \mathrm{AP} / \mathrm{g}$ carrier); $l_{4 A P, p}$ - the amount of $4 \mathrm{AP}$ in the pores (g $4 \mathrm{AP} / \mathrm{g}$ carrier); $m_{c}$-the amount of carrier $(\mathrm{g}) ; W$ - the weight loss calculated from the TG curve (g); $W_{c l s}$-the weight loss of the drug-loaded carriers between $30-225{ }^{\circ} \mathrm{C}$ and $225-1000{ }^{\circ} \mathrm{C} ; W_{c}$-the weight loss of the carrier also in these temperature ranges.

Electrochemical measurements were performed with an AutoLab potentiostat (PGSTAT302N EcoChemie, Utrecht, Netherlands) controlled by FRA 2.1 software for impedance measurements. The experimental impedance data were fitted using ZSimpWin 3.21 software and an appropriate equivalent electric circuit in order to correlate the values of circuit components with the processes occurring in the electrochemical cell. The $\mathrm{pH}$ measurements were made using a glass electrode connected to a Pracitronic $\mathrm{pH}$ meter (Dresden, Germany).

\subsection{Preparation of HAP and $S i-H A P$}

$\mathrm{HAP}$ was prepared by precipitation method as previously described [12]. Briefly, the $0.15 \mathrm{M} \mathrm{Ca}\left(\mathrm{NO}_{3}\right)_{2} \cdot 4 \mathrm{H}_{2} \mathrm{O}$ solution was added to the $0.09 \mathrm{M}\left(\mathrm{NH}_{4}\right)_{2} \mathrm{HPO}_{4}$ solution under vigorous stirring, and ammonia solution (25\%) was used to adjust the $\mathrm{pH}$ to 11 . The $\mathrm{Si}-$ $\mathrm{HAP}$, with 10 mass \% of silica, was prepared by mixing firstly $0.0032 \mathrm{M} \mathrm{Na}_{2} \mathrm{SiO}_{3}$ with the $\mathrm{Ca}^{2+}$ precursor, and then the $0.09 \mathrm{M}\left(\mathrm{NH}_{4}\right)_{2} \mathrm{HPO}_{4}$ solution was added to the resulting solution. Both mixtures were stirred at room temperature for $24 \mathrm{~h}$ and then washed three times with distilled water. The white precipitate was dried for $24 \mathrm{~h}$ at $105^{\circ} \mathrm{C}$.

\subsection{Adsorption of 4AP on HAP and Si-HAP Carriers}

The following procedure was used to prepare HAP-4AP and Si-HAP-4AP drugloaded carriers. Different concentrations $(5,10,15,17,20,25 \mathrm{wt} \%)$ of $4 \mathrm{AP}$ solutions were prepared by dissolving appropriate amounts of $4 \mathrm{AP}$ powder in distilled water. The drug solutions were mixed with the $0.1 \mathrm{~g}$ of dried powder carriers (HAP or Si-HAP) and the mixture was stirred for $24 \mathrm{~h}$ with vigorous, constant stirring. After the adsorption time, the suspension was centrifuged ( $5500 \mathrm{rpm}, 16 \mathrm{~min}$ ). The solid phase was dried for $24 \mathrm{~h}$ at $40{ }^{\circ} \mathrm{C}$, while the concentration of the aqueous phases was measured spectrophotometrically at $262 \mathrm{~nm}$. The series of experiments was repeated three times, the main values being reported.

\subsection{Electrochemical Measurements}

For electrochemical measurements, a conventional three-electrode cell, equipped with a working electrode of Ti electrode, an $\mathrm{Ag} / \mathrm{AgCl}, \mathrm{KCl}_{\text {sat }}$ reference electrode, and a platinum wire auxiliary electrode, was used to investigate the drug release properties by ion leaching from HAP and Si-HAP coatings containing 4AP (HAP_4AP_25 and SiHAP_4AP_25 samples). Impedance spectra for Ti electrode were recorded at the OCP value (obtained after $10 \mathrm{~min}$ ), by using an $\mathrm{AC}$ signal with an amplitude of $\pm 10 \mathrm{mV}$ and a frequency interval from $10 \mathrm{kHz}$ down to $0.01 \mathrm{~Hz}$. EIS data were plotted as Nyquist and Bode diagrams. The working Ti electrode was prepared as follows. Before use, the Ti surface was polished on alumina slurry (of successive gradations: 500, 1000, and 4000) and then thoroughly washed with distilled water. Then, $1 \mathrm{mg}$ of the composite was dispersed in $1 \mathrm{~mL}$ of chitosan solution prepared with $0.1 \mathrm{M}$ acetic acid and was sonicated for $2 \mathrm{~h}$. By the drop-casting method, a volume of $6 \mu \mathrm{L}$ was deposited on the Ti surface and kept at room temperature for drying, until the solvent evaporated.

\subsection{Desorption of 4AP from HAP Composites}

Composites containing 4AP were compressed using a manual Specac Atlas 15T hydraulic press (Fort Washington, MD, USA). The tablets were soaked in $20 \mathrm{~mL}$ of SBF. The release of the drug was examined with spectrophotometer measurements, at $262 \mathrm{~nm}$, at defined time intervals $(15,30,45,60,75,90,105,120,135,150,165,180,240,300,360,420$, $480 \mathrm{~min})$. After each measurement, the sample solution was replaced with fresh SBF. 


\section{Results and Discussion}

\subsection{UV-VIS Spectrophotometric Study of Adsorption}

Figure 1 shows the average adsorption capacity of the carriers as a function of different concentrations of initial 4AP solutions. There was no significant difference between the values of the individual measurements, and the standard deviation between experimental replicates is in the range of $0.7-4.2 \%$. The average adsorption efficiency was $95-98 \%$. The highest adsorption capacity was achieved for both carriers with the $25 \mathrm{~g} / \mathrm{L} 4 \mathrm{AP}$ solution (1231.1 mg/g and $1243.84 \mathrm{mg} / \mathrm{g}$ for HAP and Si-HAP carriers).

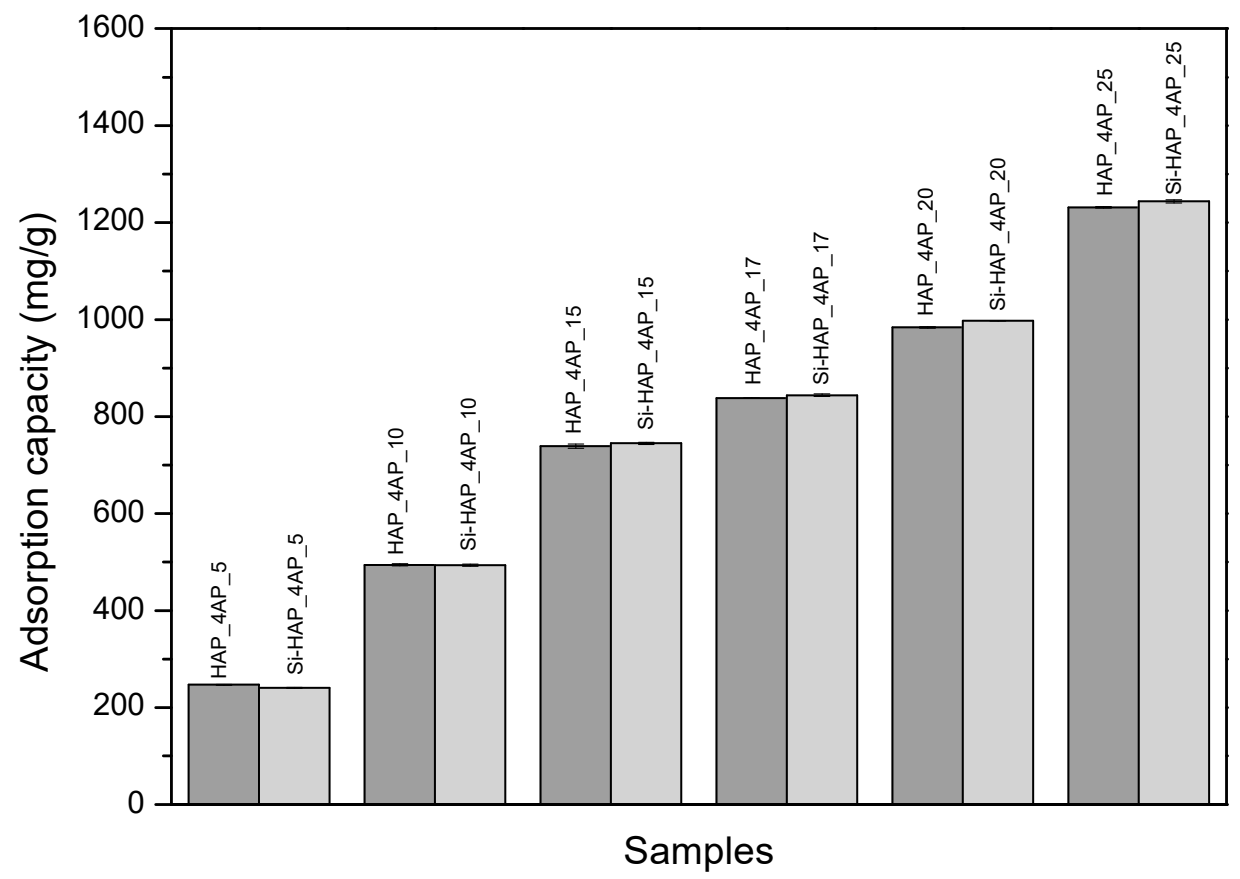

Figure 1. Adsorption capacity of 4AP-loaded onto HAP (gray) and Si-HAP (light gray) carriers.

The adsorption capacity is influenced not only by the nature of the carrier but also by the concentration of the adsorbed drug [48]. In the present study, the initial concentration of $4 \mathrm{AP}$ is the main parameter because the loading of the carriers increases proportionally with the increase of the initial 4AP concentration.

The increase of the adsorption capacity could be explained by the physical sorption process [49], during which selective bonds are formed between the pyridine ring nitrogen lone pairs of $4 \mathrm{AP}$ drug and the surface functional groups $(-\mathrm{OH},-\mathrm{Si}-\mathrm{OH})$ of the carrier's matrix [42].

Moreover, in the case of the Si-HAP carrier, a competition between water and drug molecules may occur during the adsorption of $4 \mathrm{AP}$ on the $-\mathrm{Si}-\mathrm{OH}$ group. The presence of water molecules reduces the number of free silanol groups; consequently, the binding of the active substance from an aqueous solution cannot be maximized [49].

\subsection{Thermal Analyses}

The results of thermogravimetry (TG) and differential thermal analysis (DTA) of carriers (HAP, Si-HAP), drug-loaded carriers (HAP_4AP_25 and Si-HAP_4AP_25), and drugs (4AP) are illustrated in Figure 2, and the most representative data are shown in Table 1. The decomposition mechanisms of 4AP and HAP have been interpreted based on the literature data [50-52]. 

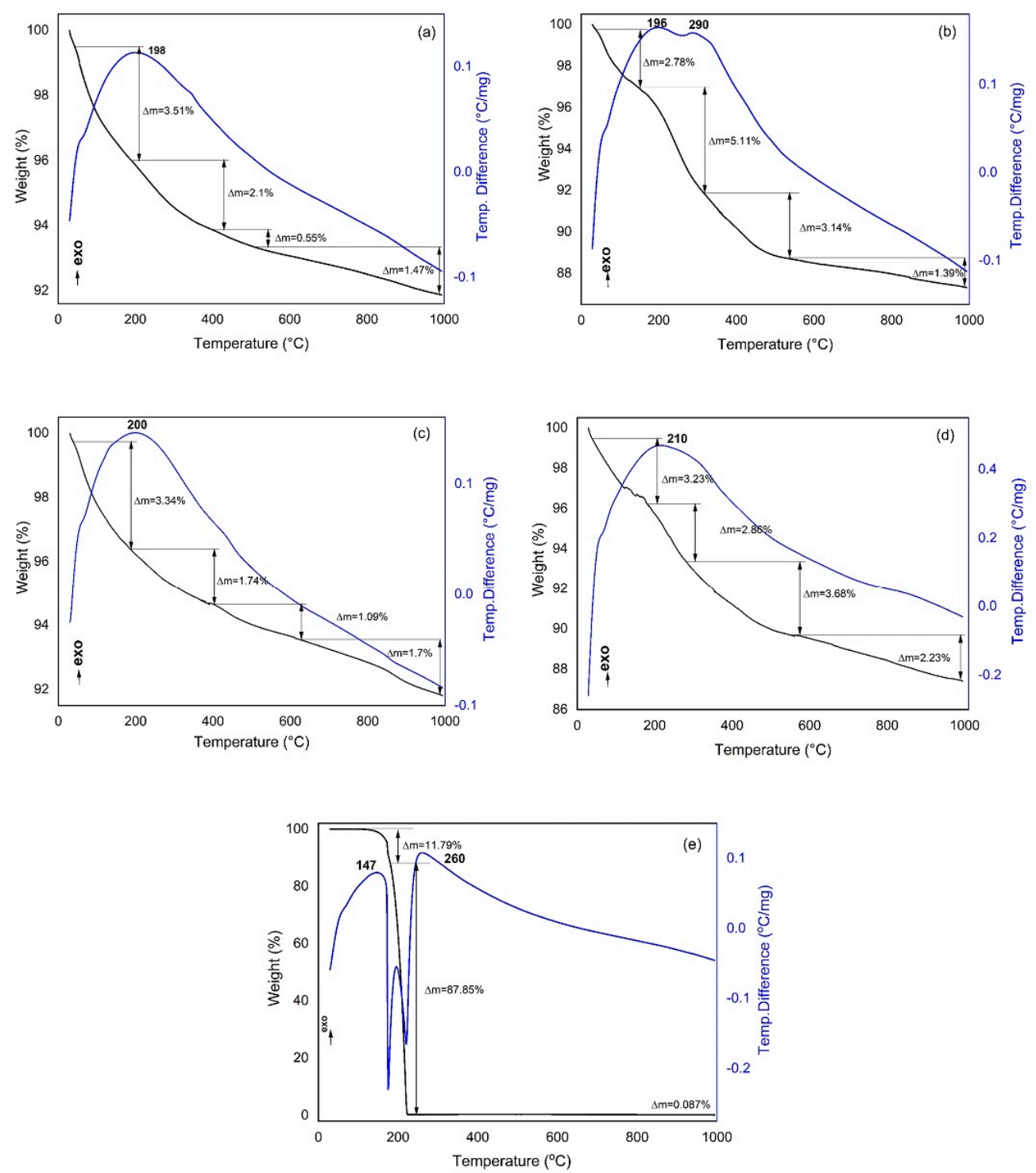

Figure 2. TG (black)/DTA (blue) plot of (a) HAP, (b) HAP_4AP_25, (c) Si-HAP, (d) Si-HAP_4AP_25 and (e) $4 \mathrm{AP}$, respectively.

In the case of $4 \mathrm{AP}$, no modification in mass was observed up to $120^{\circ} \mathrm{C}$, and the melting processes started between $120-180{ }^{\circ} \mathrm{C}$ [50]. By increasing the temperature, the sample decomposed completely within a small temperature range $\left(180-225^{\circ} \mathrm{C}\right)$.

The weight losses of the HAP_4AP sample were caused by similar processes as in the case of HAP. However, the presence of $4 \mathrm{AP}$ as an additive led to a change in the decomposition mechanism. The mass loss in HAP_4AP was higher (5.11\%) compared to the one in HAP, in the range of $150-315{ }^{\circ} \mathrm{C}$, which was probably the result of the decomposition of $4 \mathrm{AP}$ in the sample.

During the thermal analysis of Si-HAP, more than $91 \%$ of the sample did not decompose at $1000{ }^{\circ} \mathrm{C}$; this value was similar to that of the HAP sample (91.6\%). The decomposition processes were similar to those described for HAP (Table 1); however, in the range of $400-600{ }^{\circ} \mathrm{C}$, the decomposition of $\mathrm{Si}-\mathrm{HAP}$ was associated with greater weight loss $(0.55 \%$ and $1.09 \%$ for HAP and $\mathrm{Si}-\mathrm{HAP}$, respectively). This phenomenon could be attributed to the water-binding effect of $\mathrm{SiO}_{2}$ [11]. 
Table 1. Weight loss (wt \%) of HAP, 4AP, and HAP_4AP_25, and occurring processes during the thermal analysis.

\begin{tabular}{|c|c|c|c|c|c|c|}
\hline \multirow{2}{*}{ Processes } & \multicolumn{2}{|r|}{ HAP } & \multicolumn{2}{|r|}{ 4AP } & \multicolumn{2}{|c|}{ HAP_4AP_25 } \\
\hline & $\mathrm{T}\left({ }^{\circ} \mathrm{C}\right)$ & Weight Loss (wt \%) & $\mathrm{T}\left({ }^{\circ} \mathrm{C}\right)$ & Weight Loss (wt \%) & $\mathrm{T}\left({ }^{\circ} \mathrm{C}\right)$ & Weight Loss (wt \%) \\
\hline Dehydration and dehydroxylation & $30-190$ & 3.51 & - & - & $30-150$ & 2.78 \\
\hline Melting of $4 \mathrm{AP}$ & - & - & $120-180$ & 11.79 & - & - \\
\hline Elimination of $4 \mathrm{AP}$ & - & - & $180-225$ & 87.85 & - & - \\
\hline $\mathrm{CO}_{3}{ }^{2-}$ elimination & $200-400$ & 2.1 & - & - & $150-315$ & 5.11 \\
\hline $\begin{array}{c}\text { Elimination of } \mathrm{H}_{2} \mathrm{O} \text { from the pores } \\
\text { Decomposition of }\end{array}$ & $390-500$ & 0.55 & - & - & $315-540$ & 3.14 \\
\hline $\begin{array}{c}\mathrm{Ca}_{x}\left(\mathrm{PO}_{4}\right)_{\mathrm{y}}(\mathrm{OH})_{\mathrm{z}} \\
\text { Reaction of } \mathrm{P}_{2} \mathrm{O}_{7}^{4-} \text { and } \mathrm{OH}^{-}\end{array}$ & $500-1000$ & 1.47 & - & - & $540-1000$ & 1.39 \\
\hline
\end{tabular}

The values of the adsorption capacity obtained from the UV-VIS spectrophotometric measurements were compared with those calculated using the TG curves. The calculations were performed according to the procedure used in others' study [47]. Based on the UV-VIS analysis, the HAP_4AP_25 sample contained $1.231 \mathrm{~g} 4 \mathrm{AP} / \mathrm{g}$ HAP active substance, while the Si-HAP_4AP_25 contained $1.243 \mathrm{~g}$ 4AP/g Si-HAP.

Based on the TG curve, $4 \mathrm{AP}$ decomposed almost $100 \%$ at $225^{\circ} \mathrm{C}$. The content of $4 \mathrm{AP}$ was calculated in two intervals: $30-225^{\circ} \mathrm{C}$ (surface) and $225-1000{ }^{\circ} \mathrm{C}$ (pores).

The calculated amount of $4 \mathrm{AP}$ bound on the surface and pores, using the equations from Section 2 (Materials and Methods), is further discussed. Accordingly, the amount of $4 \mathrm{AP}$ bound on the surface of HAP was $l_{4 A P, s}=0.6446$ (g $\left.4 \mathrm{AP} / \mathrm{g} \mathrm{HAP}\right)$, and it could not be precisely determined in the pores because the carbonate content of the sample was probably too high [11].

Similarly, in the case of the Si-HAP carrier, the amount of $4 \mathrm{AP}$ bound on the surface and pores was $l_{4 A P, s}=0.22 \mathrm{~g} 4 \mathrm{AP} / \mathrm{g} \mathrm{Si}-\mathrm{HAP}$ and $l_{4 A P, p}=1.063 \mathrm{~g} 4 \mathrm{AP} / \mathrm{g}$ Si-HAP, respectively. Thus, it was clear that the total $4 \mathrm{AP}$ content of the sample according to the TG analysis was $1.283 \mathrm{~g} 4 \mathrm{AP} / \mathrm{g} \mathrm{Si}-\mathrm{HAP}$, a value that was very close to the estimated amount obtained by the UV-VIS spectrophotometric analysis (1.243 g 4AP/g Si-HAP).

\subsection{Fourier Transform Infrared Spectroscopy (FTIR) Analysis}

The FTIR spectra of the HAP and Si-HAP samples loaded with a $25 \mathrm{~g} / \mathrm{L} 4 \mathrm{AP}$ initial solution is shown in Figure 3. The vibration spectra of $4 \mathrm{AP}$ and the carriers were given as references. There was no significant difference between the spectra of HAP and HAP_4AP_25. Specific vibrations of HAP appeared in both cases. The O-P-O vibration appeared at the lowest wavenumber $\left(634.6 \mathrm{~cm}^{-1}\right)$. The less intense, symmetrical vibrations of $\mathrm{P}-\mathrm{O}$ gave a signal at $960.5 \mathrm{~cm}^{-1}$. The highest intensity signals in the spectrum confirmed the presence of the phosphate ion (1024.2-1097.4 $\left.\mathrm{cm}^{-1}\right)$. The group of the $\mathrm{CO}_{3}{ }^{2-}$ was observed at $1409.9,1448.5,1529.5$, and $1658.7 \mathrm{~cm}^{-1}$ [53].

In the spectrum of Si-HAP, the stretching vibrations of $\mathrm{Si}-\mathrm{O}-\mathrm{Si}$ resulted in distorting the most intense peak. Thus, the peak distortion caused by $\mathrm{Si}-\mathrm{O}-\mathrm{Si}$ is most significant in the range of 1006-1118 $\mathrm{cm}^{-1}$; however, the peaks cannot be clearly identified due to the presence of the phosphate groups [11].

Identification of drug presence in the HAP_4AP_25 and Si-HAP_4AP_25 spectra was not clear, because the intensity of the $4 \mathrm{AP}$ peaks was less than the intensity of the peaks of HAP and Si-HAP. The given signal of $829.4 \mathrm{~cm}^{-1}$ (see supplementary materials), which refers to the $\mathrm{C}-\mathrm{H}$ bond, has proven the presence of 4AP in the HAP_4AP_25 and Si-HAP_4AP_25 samples, with a very low signal. Similarly, the vibration belonging to the $\mathrm{NH}_{2}$ group of $4 \mathrm{AP}$ was detected around the $3074.4-3186.3 \mathrm{~cm}^{-1}$ wavenumber. 


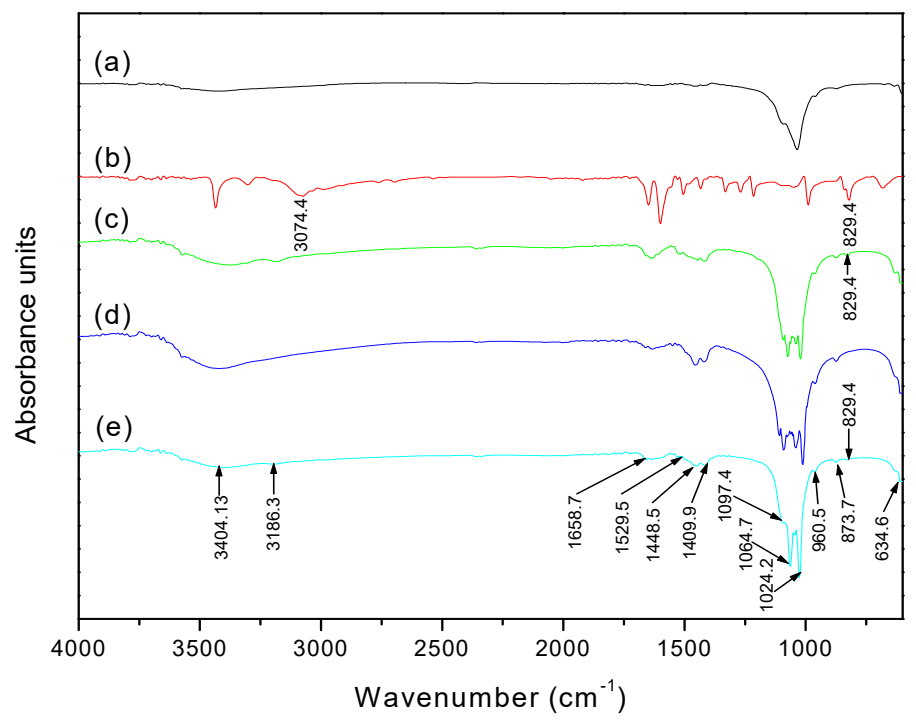

Figure 3. FTIR spectra of (a) HAP, (b) 4AP, (c) HAP_4AP_25, (d) Si-HAP, and (e) SiHAP_4AP_25 samples.

\subsection{Scanning Electron Microscopy (SEM)/Energy Dispersive X-ray (EDX)}

The morphology of the carriers and drug-loaded carriers were examined using SEM coupled to an EDX detector (Figure 4). No significant differences were observed between pure carriers and samples containing the active substances. The particles were concisely arranged and were elongated and rounded in shape. This property is characteristic of HAP-based materials prepared by the precipitation method [51]. No increase in particle size was observed after $4 \mathrm{AP}$ adsorption, and the main diameter values were similar for HAP and HAP_4AP_25 and Si-HAP_4AP_25, respectively.

(a)

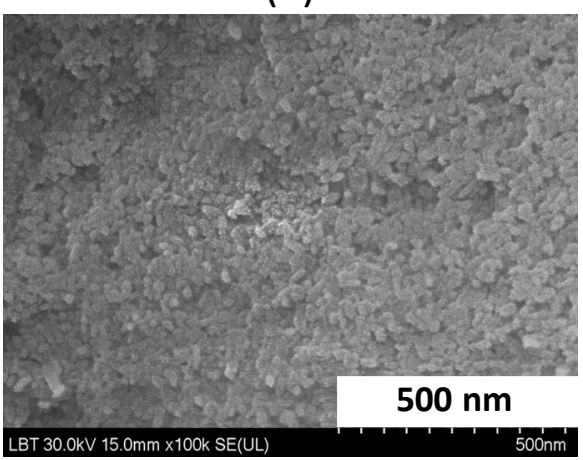

(c)

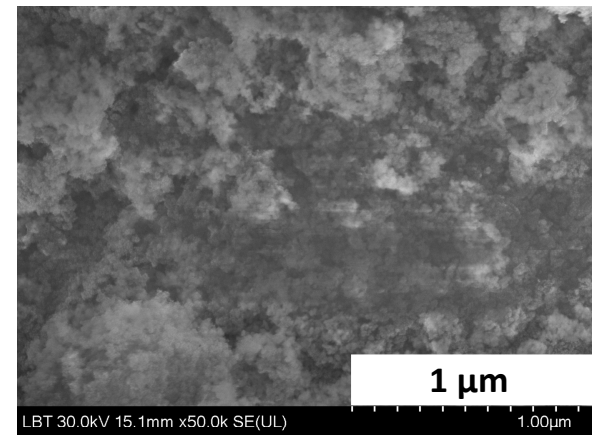

(b)

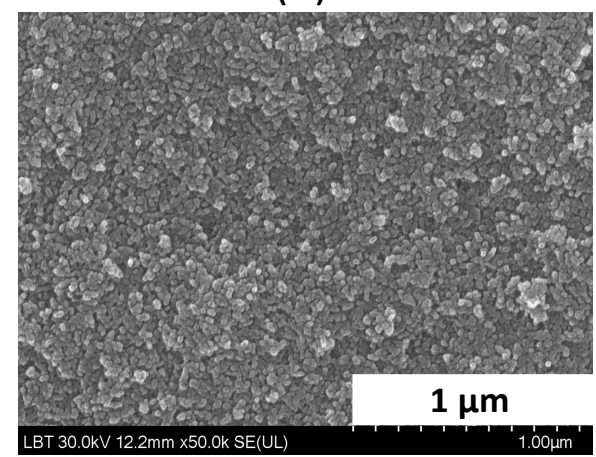

(d)

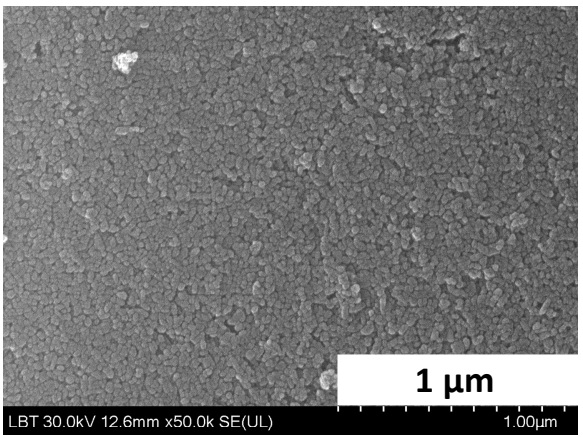

Figure 4. SEM images for (a) HAP, (b) HAP_4AP_25, (c) Si-HAP, and (d) Si-HAP_4AP_25, respectively. 
EDX analyses were performed to detect chemical elemental composition on the surface of the samples. The results of EDX analysis highlight the simultaneous presence of the $\mathrm{Ca}$, $\mathrm{P}, \mathrm{Si}$. Na, C and O elements, and no others were systematically detected. EDX analysis confirmed the success of $\mathrm{Na}_{2} \mathrm{SiO}_{3}$-modified HAP production because the silicon content of the sample was detectable. EDX analysis was able to detect the presence of $4 \mathrm{AP}$ bound on the surface of the carriers by detecting the nitrogen atom. In samples HAP_4AP_25 and Si-HAP_4AP_25, the wt \% of the nitrogen is similar, which also justifies the UVVIS spectrophotometric measurements (Figure 1). Similarly, the $C$ atom appeared in the analysis, but this not only referred to the molecules that formed the framework of the 4AP ring but also confirmed the presence of carbonate ions in the HAP and Si-HAP samples, which had already been identified in the FTIR spectra (Figure 3).

\subsection{X-ray Powder Diffraction (XRPD)}

Figure 5 shows the XRPD diffractograms of the investigated samples. As a reference, the crystallinity of $4 \mathrm{AP}$ was also analyzed. The degree of crystallinity was estimated as the ratio between the area of all diffraction peaks and the total area of diffraction peaks and amorphous halo. The diffractograms of carriers and the drug-loaded carriers were identified based on the database: JSPDC No. 009-0432 (HAP) and JSPDC No. 0301518 (4AP) cards. The diffractogram of $4 \mathrm{AP}$ showed sharp peaks at $2 \theta$ equal to $20.07^{\circ}$, $21.39^{\circ}, 24.33^{\circ}, 29.22^{\circ}$, and $30.17^{\circ}$, respectively. Both HAP and Si-HAP-based samples were observed to have the characteristic peaks of $\operatorname{HAP}\left(25.87^{\circ}, 28.96^{\circ}, 32.90^{\circ}, 34.05^{\circ}, 39.81^{\circ}\right.$, $46.71^{\circ}, 49.46^{\circ}$, and $53.14^{\circ}$ ). The maximum intensity peak was identifiable at $2 \theta \sim 31.77^{\circ}$, and the values were similar to those reported in the literature [54]. The Miller indices for the corresponding peaks were also presented in Figure 5. Signs of by-products or other unwanted products were not observed in the diffractogram. In the diffractogram of the HAP_4AP_25 sample, the intensive peak of 4AP was identified at $2 \theta \sim 21.39^{\circ}$, which demonstrated the presence of the active substance.

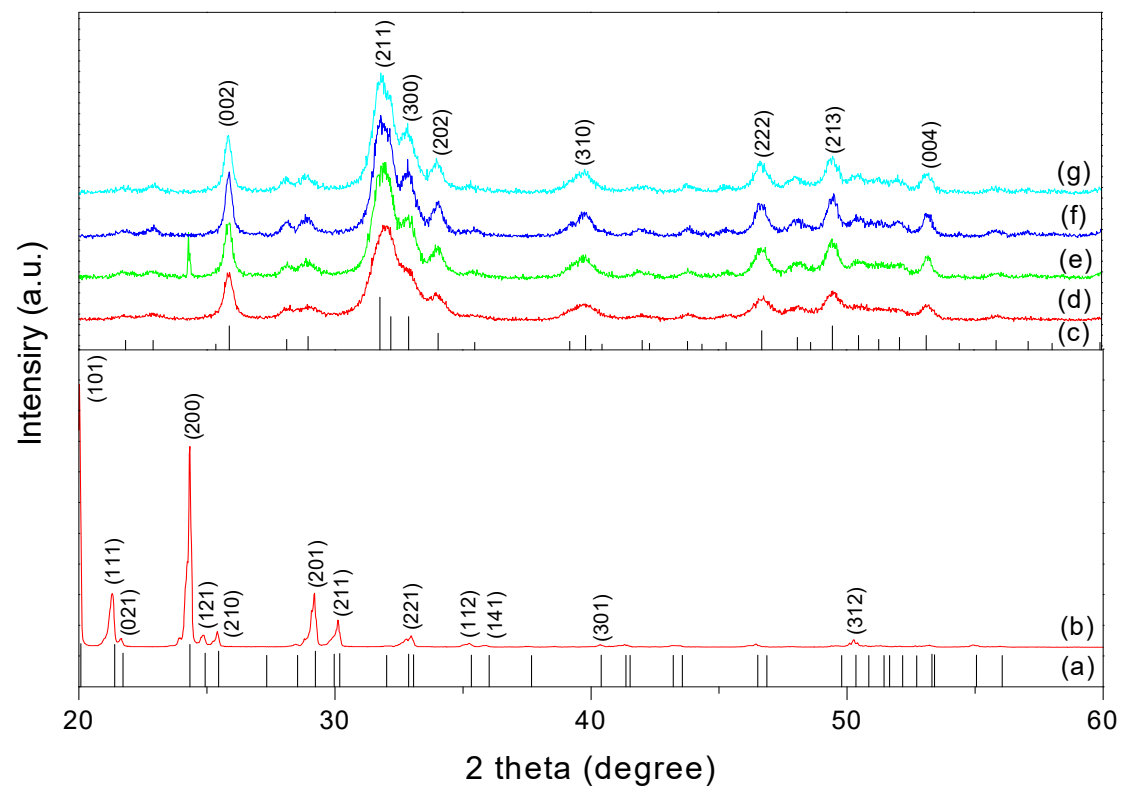

Figure 5. XRPD diffractograms of (a) 4AP-JSPDC No. 030-1518, (b) 4AP, (c) HAP-JSPDC No. 009-0432, (d) HAP, (e) HAP_4AP_25, (f) Si-HAP, and (g) Si-HAP_4AP_25, respectively.

The adsorption of $4 \mathrm{AP}$ resulted in a decrease in the degree of crystallinity for both carriers. This phenomenon was also observed during the adsorption of IBU on mesoporous silica-HAP, and it was explained by the inhibition of the recrystallization of drug molecules because the pore size of the carrier was 20 times larger than the length of the drug molecule [16]. 
In our case, after drug adsorption, the crystallinity of the HAP carrier decreased from 59.4 to $41.7 \%$, while in the case of the $\mathrm{Si}-\mathrm{HAP}$ carrier, crystallinity decreased from $81.3 \%$ to $53.38 \%$, respectively.

\subsection{Electrochemical Impedance Spectroscopy Measurements}

In order to assess the electrical properties of coatings based on HAP and modified HAP on titanium-based support as well as the beneficial presence of 4AP in HAP and Si-HAP coating, electrochemical impedance spectroscopy (EIS) measurements were performed. This investigation method is a complex and useful one, generally applied to evaluate the behavior of an electrochemical system by modeling the real system in terms of an equivalent electric circuit.

Impedance spectra were recorded after a stabilization time period of $10 \mathrm{~min}$ when the open-circuit potential considered to be optimal for reaching a quasi-equilibrium state at the electrode/solution interface was established. The obtained impedance data plotted as Nyquist and Bode diagrams (Figure 6) were fitted using a non-linear regression method, and the values of the parameters of the equivalent electrical circuit model (i.e., $R_{s}\left(Q_{\text {coat }}\right.$ $\left.\mathrm{R}_{\text {coat }}\right)\left(\mathrm{Q}_{\mathrm{ct}} \mathrm{Rct}\right)$ ) [55] were summarized in Table 2.

It must be highlighted that for all-coated surfaces, $\mathrm{Q}_{\text {coat }}$ and $\mathrm{R}_{\text {coat }}$ represent the constant phase element and polarization resistance of the composite coating, $Q_{c t}$ and $R_{c t}$ represent the constant phase element and polarization resistance of the charge transfer, and $R_{\text {sol }}$ value represents the solution resistance. The value of the roughness factor $n$ for these layers represents their ability to have a behavior close to an ideal capacitor when $n$ is close to 1 [56,57]. All studied composites have the same behavior either in a standard redox probe $\left(5 \mathrm{mM} \mathrm{K}_{3}[\mathrm{Fe}(\mathrm{CN})]_{6} / \mathrm{K}_{4}[\mathrm{Fe}(\mathrm{CN})]_{6}+0.1 \mathrm{M} \mathrm{KCl}\right)$ or in an SBF at pH 7 . The Nyquist spectra show a decreased diameter of the semicircle at high frequencies, which is typical behavior for a porous coating on a metallic substrate [58,59].
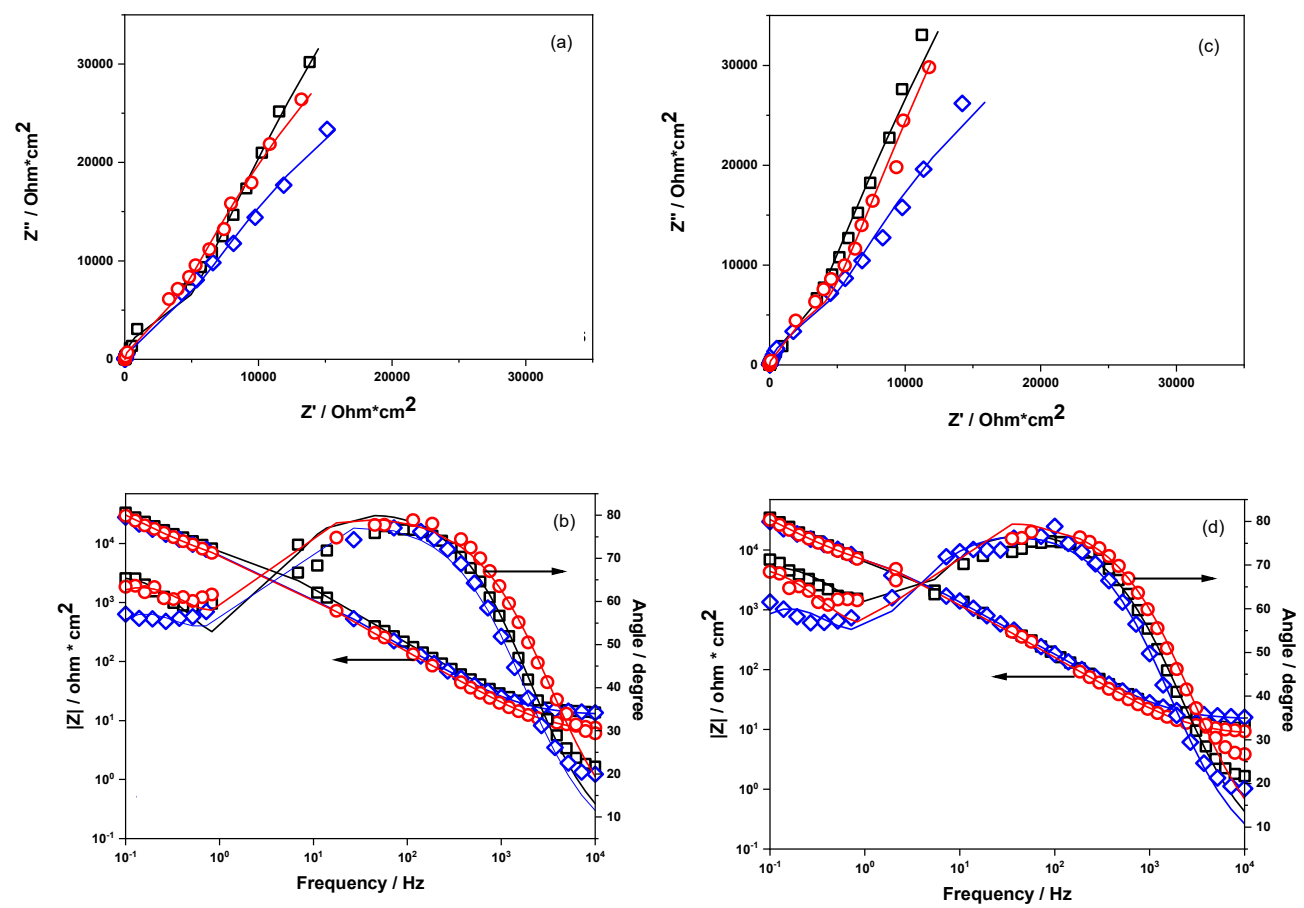

Figure 6. Nyquist $(\mathbf{a}, \mathbf{c})$ and Bode $(\mathbf{b}, \mathbf{d})$ impedance spectra recorded for HAP-Chit/Ti $(\square)$, HAP_4AP_25-Chit/Ti $(\diamond)$, and Si-HAP_4AP_25-Chit/Ti $(\mu)$ coatings exposed to $5 \mathrm{mM}$ $\mathrm{K}_{3}[\mathrm{Fe}(\mathrm{CN})]_{6} / \mathrm{K}_{4}[\mathrm{Fe}(\mathrm{CN})]_{6}+0.1 \mathrm{M} \mathrm{KCl}(\mathbf{a}, \mathbf{b})$ and $\mathrm{SBF}(\mathbf{c}, \mathbf{d})$ solutions of $\mathrm{pH} 7$. The line is the fitting curve of the experimental data using the electric equivalent circuit model $R_{s}\left(Q_{\text {coat }} R_{c o a t}\right)\left(Q_{c t} R_{c t}\right)$. 
Table 2. EIS parameters of HAP-Chit/Ti, HAP_4AP_25-Chit/Ti, and Si-HAP_4AP_25-Chit/Ti coatings.

\begin{tabular}{|c|c|c|c|c|c|c|}
\hline \multirow{2}{*}{$\begin{array}{l}\text { Circuit } \\
\text { Parameters }\end{array}$} & \multicolumn{3}{|c|}{$\begin{array}{c}5 \mathrm{mM} \mathrm{K}_{3}[\mathrm{Fe}(\mathrm{CN})]_{6} / \mathrm{K}_{4}[\mathrm{Fe}(\mathrm{CN})]_{6}+ \\
0.1 \mathrm{M} \mathrm{KCl} \mathrm{Solution,} \mathrm{pH} 7\end{array}$} & \multicolumn{3}{|c|}{ SBF Solution, pH 7} \\
\hline & HAP & $\begin{array}{l}\text { HAP }_{-} \\
\text {4AP_25 }\end{array}$ & $\begin{array}{l}\text { Si-HAP } \\
\text { 4AP_25 }\end{array}$ & HAP & $\begin{array}{l}\text { HAP }_{-} \\
\text {4AP_25 }\end{array}$ & $\begin{array}{l}\text { Si-HAP_- } \\
\text { 4AP_25 }\end{array}$ \\
\hline $\begin{array}{c}\mathrm{R}_{\mathrm{sol}} / \\
\mathrm{ohm} \cdot \mathrm{m}^{2}\end{array}$ & $\begin{array}{l}12.54 \\
\pm 5.15\end{array}$ & $\begin{array}{l}12.38 \\
\pm 4.05\end{array}$ & $\begin{array}{c}6.26 \\
\pm 4.92\end{array}$ & $\begin{array}{l}11.83 \\
\pm 2.93\end{array}$ & $\begin{array}{l}14.68 \\
\pm 4.01\end{array}$ & $\begin{array}{l}8.07 \\
\pm 5.58\end{array}$ \\
\hline $\begin{array}{c}\mathrm{Q}_{\text {coat }} / \\
\mathrm{S} \cdot \mathrm{s}^{\mathrm{n}} / \mathrm{cm}^{2}\end{array}$ & $\begin{array}{c}4.36 \times 10^{-5} \\
\pm 5.02\end{array}$ & $\begin{array}{l}3.01 \times 10^{-5} \\
\pm 21.62\end{array}$ & $\begin{array}{c}3.17 \times 10^{-5} \\
\pm 31.3\end{array}$ & $\begin{array}{l}4.2 \times 10^{-5} \\
\pm 2.44\end{array}$ & $\begin{array}{l}2.81 \times 10^{-5} \\
\pm 9.97\end{array}$ & $\begin{array}{c}2.52 \times 10^{-5} \\
\pm 33.79\end{array}$ \\
\hline $\mathrm{n}$ & 0.8430 & 0.9177 & 0.9745 & 0.8405 & 0.9065 & 1 \\
\hline $\begin{array}{c}\mathrm{R}_{\text {coat }} / \\
\mathrm{ohm} \cdot \mathrm{cm}^{2}\end{array}$ & $\begin{array}{l}3.99 \times 10^{5} \\
\pm 10.41\end{array}$ & $\begin{array}{l}4534 \\
\pm 7.17\end{array}$ & $\begin{array}{l}3003 \\
\pm 32.8\end{array}$ & $\begin{array}{l}7.79 \times 10^{5} \\
\pm 10.39\end{array}$ & $\begin{array}{l}4186 \\
\pm 6.42\end{array}$ & $\begin{array}{c}3130 \\
\pm 30.31\end{array}$ \\
\hline $\begin{array}{c}\mathrm{Q}_{\mathrm{ct}} / \\
\mathrm{S} \cdot \mathrm{s}^{\mathrm{n}} / \mathrm{cm}^{2}\end{array}$ & $\begin{array}{c}1.55 \times 10^{-5} \\
\pm 23.44\end{array}$ & $\begin{array}{c}5.38 \times 10^{-5} \\
\pm 13.24\end{array}$ & $\begin{array}{c}4.88 \times 10^{-5} \\
\pm 5.26\end{array}$ & $\begin{array}{c}2.64 \times 10^{-5} \\
\pm 15.17\end{array}$ & $\begin{array}{c}4.89 \times 10^{-5} \\
\pm 8.69\end{array}$ & $\begin{array}{c}4.60 \times 10^{-5} \\
\pm 6.37\end{array}$ \\
\hline $\mathrm{n}$ & 1 & 0.8631 & 0.8483 & 0.9673 & 0.8719 & 0.8421 \\
\hline $\begin{array}{c}\mathrm{R}_{\mathrm{ct}} / \\
\mathrm{ohm} \cdot \mathrm{cm}^{2}\end{array}$ & $\begin{array}{c}3.8 \times 10^{3} \\
\pm 19.8\end{array}$ & $\begin{array}{l}1.04 \times 10^{5} \\
\quad \pm 5.64\end{array}$ & $\begin{array}{l}1.88 \times 10^{5} \\
\quad \pm 4.45\end{array}$ & $\begin{array}{c}2.16 \times 10^{3} \\
\pm 23.56\end{array}$ & $\begin{array}{l}1.26 \times 10^{5} \\
\pm 6.36\end{array}$ & $\begin{array}{c}6.78 \times 10^{5} \\
\pm 20.02\end{array}$ \\
\hline $\mathrm{C}_{\text {coat }} / \mathrm{F} \cdot \mathrm{cm}^{-2}$ & $7.41 \times 10^{-5}$ & $2.51 \times 10^{-5}$ & $2.98 \times 10^{-5}$ & $8.13 \times 10^{-5}$ & $2.25 \times 10^{-5}$ & $2.53 \times 10^{-5}$ \\
\hline$x^{2}$ & $9.25 \times 10^{-3}$ & $4.14 \times 10^{-3}$ & $5.22 \times 10^{-3}$ & $2.87 \times 10^{-3}$ & $5.71 \times 10^{-3}$ & $8.06 \times 10^{-3}$ \\
\hline
\end{tabular}

Values \pm represent relative standard errors (RSD) expressed in percent $(\%)$.

The $\mathrm{R}_{\mathrm{ct}}$ is a quantitative parameter, which indicates the hindering of the electron transfer process through the composite matrix [59].

As it can be seen in Table 2, in the case of HAP-Chit coating, $R_{\text {coat }}$ has high values $\left(3.99 \times 10^{5}\right.$ and $\left.7.79 \times 10^{5} \mathrm{ohm} \cdot \mathrm{cm}^{2}\right)$ and $R_{\text {ct }}$ has low values $\left(3.8 \times 10^{3}\right.$ or $\left.2.16 \times 10^{3} \mathrm{ohm} \cdot \mathrm{cm}^{2}\right)$, which demonstrates that the electrolyte could not traverse the coating to arrive at the electrode/coating interface, and a very thin passive oxide layer has probably formed on the Ti [60]. This behavior may be explained by the structural arrangement of the nonconductive calcium phosphate component of the HAP-Chit coating, but because the layer is quite thin, the entering of an aggressive ion such as $\mathrm{Cl}^{-}$from both tested electrolytes gives rise to a charge transfer process [6]. However, the presence of $4 \mathrm{AP}$, which has a certain dimension and 3D structure, contributes to enlarging the porosity of either the $\mathrm{HAP}$ or $\mathrm{Si}-\mathrm{HAP}$ composites or that of the polymer (chitosan), or it contributes to reducing surface defects [6] by a leveling effect (a hypothesis confirmed by the increase of $n$ values), leading to a decrease of the $\mathrm{R}_{\text {coat }}\left(\sim 10^{3} \mathrm{ohm} \cdot \mathrm{cm}^{2}\right)$ and an approximately 100 time increase of the $\mathrm{R}_{\mathrm{ct}}$ values (to $\sim 10^{5} \mathrm{ohm} \cdot \mathrm{cm}^{2}$ ), compared to the simple HAP coatings. Moreover, the $\mathrm{R}_{\mathrm{ct}}$ values are pronounced higher in the case of $4 \mathrm{AP}$ adsorbed on Si-HAP composite than on simple HAP. This behavior points out the role of 4AP in the composite coating in order to hinder the electron transfer occurring at the electrode interface. This distinct behavior of Si-HAP_4AP_25-Chit coating can be explained as follows: despite the fact that strong adsorption of $4 \mathrm{AP}$ takes place due to the existence of a hydrogen-bonding interaction between the surface silanol groups and the pyridine ring nitrogen lone pairs of 4AP [42], a large porosity of the composite matrix is maintained. The coating capacities $\mathrm{C}$ (in F/ $\mathrm{cm}^{2}$ ) can be used as a measure of the permeability [61] of the composite matrix, and their values increase in the following order: HAP_4AP_25 $<$ Si-HAP_4AP_25. These values can be correlated with the increase in the thickness of the passive oxide layer on Ti/coating interface, which leads to the increase of the $\mathrm{R}_{\mathrm{ct}}$ in the same order: HAP_4AP_25 $<\mathrm{Si}-$ HAP_4AP_25; in these conditions, the charge transfer process is hindered in the case of the Si-HAP coating.

The Bode plots, regardless of the coating type, show a slope of the $|Z|$ versus $\log f$ diagram in the frequency range $10^{-3}-10^{3} \mathrm{~Hz}$ of around -0.8 and a phase angle between 
$70-80^{\circ}$ at a high frequency range, which are characteristic values for the high capacitance of the coatings [56].

The values obtained by applying the Chi-square distribution test for all the estimated parameters of the equivalent circuits are within a range of between $10^{-3}$ and $10^{-2}$, and the relatively low values of the relative standard errors (RSD) expressed in percentage (\%) indicate a good agreement between experimental and fitted data and a good choice of the electrical equivalent circuit components.

\subsection{Investigation of Drug Release}

After successfully binding $4 \mathrm{AP}$ to sample surfaces and sample pores, the possibility of using the biomaterials as drug carriers were investigated. The release profiles in time (Figure 7a,b) showed a reduced and irregular dissolution of $4 \mathrm{AP}$ in SBF for both HAP and $\mathrm{Si}-\mathrm{HAP}$ carriers, regardless of the amount of adsorbed 4AP.
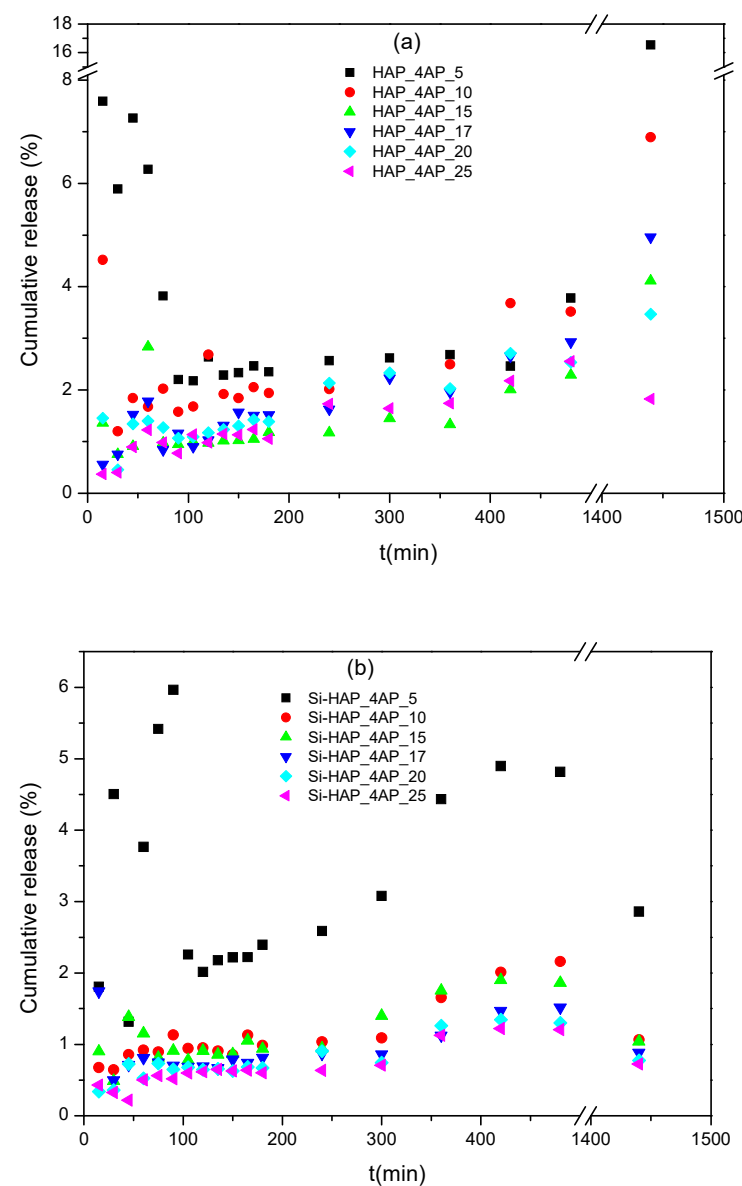

Figure 7. Cumulative release profile of 4AP from (a) HAP and (b) Si-HAP carriers.

The HAP_4AP_5 and Si-HAP_4AP_5 samples showed the most irregular behavior, especially in the first two hours of the experiment. The amount of released drug from HAP increased with the investigation time, an exception being recorded in the case of the HAP_4AP_25 sample, where the released cumulative $4 \mathrm{AP}$ decreased after $24 \mathrm{~h}$. This phenomenon could be observed for all Si-HAP_4AP samples. It is worth mentioning that in the case of the HAP carrier, the released 4AP amount was of one order of magnitude greater than in the case of Si-containing carriers. On the one hand, this could be explained by the excellent retard property of the silica-containing samples [13], and on the other hand, by the fact that less $4 \mathrm{AP}$ was bound to the surface in the case of the Si-HAP sample than in the case of HAP (see Section 3.2). Probably due to the absence of agitation during the measurement in SBF (in order to eliminate degradation of the tablets to be analyzed), the 
amount of released drug was only the result of the dissolution of $4 \mathrm{AP}$ bound to the surface. The maximum dissolution of $4 \mathrm{AP}$ did not exceed $16 \%$ for HAP-based samples in any case, while it hardly reached 3\% for Si-HAP-based carriers after $24 \mathrm{~h}$ of experiment.

It is known that the amount of drug released in the absence of mixing is a function of bonds. Electrochemical measurements prove that the presence of $\mathrm{Si}$ in the carrier may provide stronger interactions between the carrier and the drug $\left(R_{c t}\right.$ values- see Section 3.6). This phenomenon may also explain the retard effect of the Si-containing carrier.

In the case of both carriers, it could be observed that the release was more regular for samples with an increased amount of drug, following a similar mechanism. At low concentrations, instrumental errors also interfere; thus, additional measurements are required for accuracy. It is equally important to observe that none of the release profiles has shown predictive behavior.

\section{Conclusions}

Adsorption and desorption measurements were performed for hydroxyapatite (HAP) and silicon-modified hydroxyapatite (Si-HAP) with fampridine (4AP), followed by their characterization using various techniques. In this study, the use of materials and science methods typical for drug delivery was supplemented with electrochemical measurements.

Drug release experiments, performed in simulated body fluid (SBF), revealed that the drug release from $\mathrm{Si}-\mathrm{HAP}$ was five times slower than from HAP, a phenomenon which could be explained by the good chemical bonding between the silanol groups of the carrier and the 4AP functional groups. Electrochemical measurements showed that in the case of $\mathrm{Si}-\mathrm{HAP}$ coating loaded with $4 \mathrm{AP}$, the value of the polarization resistance of the charge transfer $\left(R_{c t}\right)$ was more than five times smaller than in the case of HAP coating loaded with $4 \mathrm{AP}$, so the charge transfer process was hindered. Moreover, the electrochemical impedance results showed that electron transfer was inhibited in the presence of $4 \mathrm{AP}$, which was in concordance with the previously mentioned strong bonds. The findings of this study conclude that the silicon substitution in HAP leads to good chemical bonding with the drug, and a slow release, respectively. This fact is of great importance in the biomedical field when slow drug release with a sustained duration of therapeutic activity is required.

This research with $4 \mathrm{AP}$ is new and it is the first step in a much more complex process in which we try to prove that HAP can be a perfect drug carrier that can maintain the physiological function of the human body while delivering key drugs to the body.

Supplementary Materials: The following are available online at https:/ / www.mdpi.com/article/ 10.3390/cryst11091124/s1, Figure S1: The calibration curve, Figure S2: Cumulative release profile of 4AP, Figure S3: FTIR spectrum of Si-HAP_4AP_25 sample.

Author Contributions: Conceptualization, R.B.; methodology, R.B., G.L.T., M.T., Z.K. and B.K.; software, L.M., N.-I.F. and L.B.; validation, R.B., G.L.T. and M.T.; investigation, L.M., N.-I.F., Z.K. and B.K.; writing - original draft preparation, L.M. and N.-I.F.; writing-review and editing, L.B.; visualization, R.B., G.L.T., M.T., Z.K. and B.K. and L.B.; supervision, R.B., G.L.T. and M.T. All authors have read and agreed to the published version of the manuscript.

Funding: This research received no external funding.

Institutional Review Board Statement: Not applicable.

Informed Consent Statement: Not applicable.

Data Availability Statement: Not applicable.

Acknowledgments: This study was supported by project CNCS-UEFISCDI, PN-III-P2-2.1-PED-20193664 - "Personalized intelligent matrices for tissue regeneration and meta-inflammation control" (PRIM_TISS), No. 348PED/03.08.2020 (project members: R.B. and L.B.).

Conflicts of Interest: The authors declare no conflict of interest. 


\section{References}

1. Saeedi, M.; Eslamifar, M.; Khezri, K.; Maleki, S. Biomedicine \& Pharmacotherapy Applications of nanotechnology in drug delivery to the central nervous system. Biomed. Pharmacother. 2019, 111, 666-675.

2. Du, M.; Chen, J.; Liu, K.; Xing, H.; Song, C. Recent advances in biomedical engineering of nano-hydroxyapatite including den-tistry, cancer treatment and bone repair. Compos. Part B 2021, 215, 108790. [CrossRef]

3. Taha, M.A.; Youness, R.A.; Ibrahim, M. Biocompatibility, physico-chemical and mechanical properties of hydroxyapatite-based silicon dioxide nanocomposites for biomedical applications. Ceram. Int. 2020, 46, 23599-23610. [CrossRef]

4. Gan, C.-D.; Jia, Y.-B.; Yang, J.-Y. Remediation of fluoride contaminated soil with nano-hydroxyapatite amendment: Response of soil fluoride bioavailability and microbial communities. J. Hazard. Mater. 2021, 405, 124694. [CrossRef]

5. Cheng, L.; Wu, H.; Li, J.; Zhao, H.; Wang, L. Polydopamine modified ultrathin hydroxyapatite nanosheets for anti-corrosion reinforcement in polymeric coatings. Corros. Sci. 2021, 178, 109064. [CrossRef]

6. Calabrese, G.; Petralia, S.; Franco, D.; Nocito, G.; Fabbi, C.; Forte, L.; Guglielmino, S.; Squarzoni, S.; Traina, F.; Conoci, S. A new Ag-nanostructured hydroxyapatite porous scaffold: Antibacterial effect and cytotoxicity study. Mater. Sci. Eng. C 2021, $118,111394$. [CrossRef] [PubMed]

7. Geuli, O.; Metoki, N.; Zada, T.; Reches, M.; Eliaz, N.; Mandler, D. Synthesis, coating, and drug-release of hydroxyapatite nanoparticles loaded with antibiotics. J. Mater. Chem. B 2017, 5, 7819-7830. [CrossRef]

8. Öner, M.; Yetiz, E.; Ay, E.; Uysal, U. Ibuprofen release from porous hydroxyapatite tablets. Ceram. Int. 2011, 37, $2117-2125$. [CrossRef]

9. Barabás, R.; Farkas, N.-I.; Nagy, C.L.; Cadar, O.; Moisa, C.; Bizo, L. Adsorption and desorption behavior of natural and synthetic active compounds on hydroxyapatite-based nanocomposites. Ceram. Int. 2021, 47, 8584-8592. [CrossRef]

10. Barabás, R.; de Sousa Ávila, E.; Ladeira, L.O.; Antônio, L.M.; Tötös, R.; Simedru, D.; Bizo, L.; Cadar, O. Graphene Oxides/Carbon Nanotubes-Hydroxyapatite Nanocomposites for Biomedical Applications. Arab. J. Sci. Eng. 2020, 45, 219-227. [CrossRef]

11. Bogya, E.S.; Barabas, R.; Bizo, L.; Dejeu, V.R. Preparation and characterization of silicate hydroxyapatites used for copper sorption. In Proceedings of the 11th ECERS Conference, Krakow, Poland, 21-25 June 2009; pp. 1109-1113.

12. Czikó, M.; Bogya, E.S.; Paizs, C.; Katona, G.; Konya, Z.; Kukovecz, Á.; Barabás, R. Albumin adsorption study onto hydroxyapatite-multiwall carbon nanotube based composites. Mater. Chem. Phys. 2016, 180, 314-325. [CrossRef]

13. Barabas, R.; Rigo, M.; Sarkozi, M.; Hoaghia, M.-A.; Cadar, O. Hydroxyapatite-Carbon Nanotube Composites for Drug Delivery Applications. Braz. J. Chem. Eng. 2019, 36, 913-922. [CrossRef]

14. Venkatasubbu, A.P.S.P.G.D. Sustained release of amoxicillin from hydroxyapatite nanocomposite for bone infections. Prog. Biomater. 2018, 7, 289-296.

15. Barabás, R.; Muntean, N.; Szabó, G.; Maurer, K.; Bizo, L. Preparation and characterizations of new biomaterials by anthocyanins adsorption on hydroxyapatite-based materials. Studia UBB Chem. 2017, 62, 253-268. [CrossRef]

16. Jani, A.T.; Haghighi, N.B.; Pour, M.S.H.; Aminian, M.; Molzemi, S. Hydroxyapatite incorporation into MCM-41 and study of ibuprofen drug release. J. Aust. Ceram. Soc. 2019, 56, 653-661. [CrossRef]

17. Bogya, E.S. Kinetic and Equilibrium Studies of Retention Processes on Apatitic Materials. Ph.D. Thesis, Babes-Bolyai University of Cluj-Napoca, Cluj-Napoca, Romania, 2010.

18. Mostafa, N.Y.; Hassan, H.M.; Elkader, O.A. Preparation and Characterization of $\mathrm{Na}^{+}, \mathrm{SiO}_{4}{ }^{4-}$, and $\mathrm{CO}_{3}{ }^{2-} \mathrm{Co}-\mathrm{Substituted}$ Hydroxyapatite. J. Am. Ceram. Soc. 2010, 94, 1584-1590. [CrossRef]

19. Bremmell, K.E.; Prestidge, C.A. Enhancing oral bioavailability of poorly soluble drugs with mesoporous silica based systems: Opportunities and challenges. Drug Dev. Ind. Pharm. 2018, 45, 349-358. [CrossRef]

20. Wu, J.; Zhu, Y.J.; Cao, S.W.; Chen, F. Hierachically nanostructured mesoporous spheres of calcium silicate hydrate: Surfactant-free sonochemical synthesis and drug-delivery system with ultrahigh drug-loading capacity. Adv. Mater. 2010, 22, 749-753. [CrossRef] [PubMed]

21. Aghaei, H.; Nourbakhsh, A.A.; Karbasi, S.; Javadkalbasi, R.; Rafienia, M.; Nourbakhsh, N.; Bonakdar, S.; MacKenzie, K.J.D. In-vestigation on bioactivity and cytotoxicity of mesoporous nano-composite MCM-48/hydroxyapatite for ibuprofen drug delivery. Ceram. Int. 2014, 40, 7355-7362. [CrossRef]

22. Dos Apostolos, R.C.R.; Andrade, G.F.; Silva, W.; Gomes, D.D.A.; Miranda, M.; De Sousa, E.M.B. Hybrid polymeric systems of mesoporous silica/hydroxyapatite nanoparticles applied as antitumor drug delivery platform. Int. J. Appl. Ceram. Technol. 2019, 16, 1836-1849. [CrossRef]

23. Sousa, A.; Souza, K.; Sousa, E. Mesoporous silica/apatite nanocomposite: Special synthesis route to control local drug delivery. Acta Biomater. 2008, 4, 671-679. [CrossRef]

24. Albrecht, P.; Bjørnå, I.K.; Brassat, D.; Farrell, R.; Feys, P.; Hobart, J.; Hupperts, R.; Linnebank, M.; Magdič, J.; Oreja-Guevara, C.; et al. Prolonged-release fampridine in multiple sclerosis: Clinical data and real-world experience. Report of an expert meeting. Ther. Adv. Neurol. Disord. 2018, 11, 1-8. [CrossRef]

25. Rommer, P.S.; Weber, M.S.; Illes, Z.; Zettl, U.K. Editorial: Multiple Sclerosis-From Bench to Bedside: Currents Insights Into Pathophysiological Concepts and Their Potential Impact on Patients. Front. Immunol. 2020, 11, 137. [CrossRef]

26. Hospira, Z.A. EMA Assessment report Fampyra. Report ARZ 2012, 44, 1-91.

27. Department of Health and Ageing of Australian Government. Australian Public Assessment Report for Fampridine (Fampyra); Department of Health and Ageing of Australian Government: Canberra, Australia, 2011. 
28. Dunn, J.; Blight, A. Dalfampridine: A brief review of its mechanism of action and efficacy as a treatment to improve walking in patients with multiple sclerosis. Curr. Med. Res. Opin. 2011, 27, 1415-1423. [CrossRef]

29. Malhotra, M.; Ghai, P.; Narasimhan, B.; Deep, A. Dalfampridine: Review on its recent development for symptomatic improvement in patients with multiple sclerosis. Arab. J. Chem. 2016, 9, S1443-S1449. [CrossRef]

30. Thomas, S.; Shandilya, S.; Bharti, A.; Agarwal, A. A stability indicating simultaneous dual wavelength UV-HPLC method for the determination of potential impurities in fampridine active pharmaceutical ingredient. J. Pharm. Biomed. Anal. 2012, 58, 136-140. [CrossRef]

31. Zope, M.V.; Patel, R.M.; Patel, A.; Patel, S.G. Development and validation of a stability indicating rp-hplc method for the determination of potential degradation products of difluprednate in ophthalmic emulsion. Int. J. Pharm. Pharm. Sci. 2018, 10, 79-86. [CrossRef]

32. Dharani, N.; Padmini, K.; Sumakala, S. Stability indicating RP-HPLC method development and validation for estimation of dalfampridine in its bulk and formulation. Int. J. Adv. Res. 2016, 4, 184-191. [CrossRef]

33. U.S.P. Convention. United States Pharmacopeia/National Formulary (USP 42-NF 37); U.S.P. Convention: Rockville, MD, USA, 2017.

34. Kovács, B.; Boda, F.; Fülöp, I.; Székely-Szentmiklósi, I.; Kelemen, É.K.; Kovács-Deák, B.; Székely-Szentmiklósi, B. HPLC method development for fampridine using Analytical Quality by Design approach. Acta Pharm. 2020, 70, 465-482. [CrossRef]

35. Smith, W.; Swan, S.; Marbury, T.; Henney, H. Single-Dose Pharmacokinetics of Sustained-Release Fampridine (Fampridine-SR) in Healthy Volunteers and Adults with Renal Impairment. J. Clin. Pharmacol. 2010, 50, 151-159. [CrossRef] [PubMed]

36. Achanti, S.; Katta, R.R. High-throughput liquid chromatography tandem mass spectrometry method for simultaneous determination of fampridine, paroxetine, and quinidine in rat plasma: Application to in vivo perfusion study. J. Food Drug Anal. 2016, 24, 866-875. [CrossRef]

37. Suneetha, A.; Raja, R.K. Comparison of LC-UV and LC-MS methods for simultaneous determination of teriflunomide, dimethyl fumarate and fampridine in human plasma: Application to rat pharmacokinetic study. Biomed. Chromatogr. 2016, 30, 1371-1377. [CrossRef] [PubMed]

38. Redasani, V.K.; Shaikh, G.L.; Surana, S.S. Development and validation of spectroscopic methods for the estimation of dalfampridine in bulk and in tablet formulation. Anal. Chem. Indian J. 2014, 14, 37-41.

39. Jain, V.; Dehariya, R.; Parkhe, G. Method development and validation for estimation of dalfampridine in synthetic mixture by using UV spectrophotometry and RP-HPLC. J. Pharm. Pharmacol. 2019, 1, 84-87.

40. U.S. Food and Drug Administration. Dissolution Methods, (n.d.). Available online: https://www.fda.gov/drugs/drugapprovals-and-databases / dissolution-methods-database (accessed on 8 August 2021).

41. Padash, R.; Sobhani, A.; Rahimi-Nasrabadi, M.; Mirmotahari, M.; Ehrlich, H.; Rad, A.S.; Peyravi, M. Is it possible to use X12Y12 $(\mathrm{X}=\mathrm{Al}, \mathrm{B}$, and $\mathrm{Y}=\mathrm{N}, \mathrm{P})$ nanocages for drug-delivery systems? A DFT study on the adsorption property of 4-aminopyridine drug. Appl. Phys. A 2018, 124, 582. [CrossRef]

42. Akyuz, S.; Akyuz, T. Adsorption of 3- and 4-aminopyridine on loughlinite-An IR spectroscopic study. Vib. Spectrosc. 2010, 53, 136-139. [CrossRef]

43. Szcześ, A.; Holysz, L.; Chibowski, E. Synthesis of hydroxyapatite for biomedical applications. Adv. Colloid Interface Sci. 2017, 249, 321-330. [CrossRef]

44. Nayak, A.K.; Hasnain, S.; Nanda, S.S.; Yi, D.K. Hydroxyapatite-alginate Based Matrices for Drug Delivery. Curr. Pharm. Des. 2019, 25, 3406-3416. [CrossRef] [PubMed]

45. Guillen-Romero, L.D.; Oropeza-Guzman, M.T.; López-Maldonado, E.A.; Iglesias, A.L.; Paz-González, J.A.; Ng, T.; SerenaGómez, E.; Villarreal-Gómez, L.J. Synthetic hydroxyapatite and its use in bioactive coatings. J. Appl. Biomater. Funct. Mater. 2019, 17, 2280800018817463. [CrossRef]

46. Awasthi, S.; Pandey, S.K.; Arunan, E.; Srivastava, C. A review on hydroxyapatite coatings for the biomedical applications: Experimental and theoretical perspectives. J. Mater. Chem. B 2021, 9, 228-249. [CrossRef] [PubMed]

47. Ibrahim, A.-R.; Li, X.; Zhou, Y.; Huang, Y.; Chen, W.; Wang, H.; Li, J. Synthesis of Spongy-Like Mesoporous Hydroxyapatite from Raw Waste Eggshells for Enhanced Dissolution of Ibuprofen Loaded via Supercritical CO 2. Int. J. Mol. Sci. 2015, 16, 7960-7975. [CrossRef]

48. Zhao, Q.; Wang, T.; Wang, J.; Zheng, L.; Jiang, T.; Cheng, G.; Wang, S. Template-directed hydrothermal synthesis of hydroxyapatite as a drug delivery system for the poorly water-soluble drug carvedilol. Appl. Surf. Sci. 2011, 257, 10126-10133. [CrossRef]

49. Psimadas, D.; Georgoulias, P.; Valotassiou, V.; Loudos, G. Molecular Nanomedicine Towards Cancer: ${ }^{111}$ In-Labeled Nanoparticles. J. Pharm. Sci. 2012, 101, 2271-2280. [CrossRef] [PubMed]

50. Chacón, C.; Bruno-Colmenárez, J.; Jamalis, J.; Delgado, G.E. Synthesis, thermal studies and crystal structure of 4-aminopyridinium semi-oxalate hemihydrate, Scientific Study \& Research. Chem. Chem. Eng. 2017, 18, 111-119.

51. Barabás, R.; Deemter, D.; Katona, G.; Batin, G.; Barabás, L.; Bizo, L.; Cadar, O. Comparative study on physicochemical and me-chanical characterization of new nanocarbon-based hydroxyapatite nanocomposites. Turk. J. Chem. 2019, 43, 809-824. [CrossRef]

52. Skwarek, E.; Janusz, W.; Sternik, D. Adsorption of citrate ions on hydroxyapatite synthetized by various methods. J. Radioanal. Nucl. Chem. 2014, 299, 2027-2036. [CrossRef] [PubMed]

53. Chandrasekar, A.; Sagadevan, S.; Dakshnamoorthy, A. Synthesis and characterization of nano-hydroxyapatite (n-HAP) using the wet chemical technique. Int. J. Phys. Sci. 2013, 8, 1639-1645. 
54. Kim, H.; Mondal, S.; Bharathiraja, S.; Manivasagan, P.; Moorthy, M.S.; Oh, J. Optimized Zn-doped hydroxyapatite/doxorubicin bioceramics system for efficient drug delivery and tissue engineering application. Ceram. Int. 2018, 44, 6062-6071. [CrossRef]

55. Jeong, Y.H.; Brantley, W.A.; Choe, H.C. AC impedance behavior of silicon-hydroxyapatite doped film on the Ti-35Nb-xZr alloy by EB-PVD method. Surf. Coat. Technol. 2013, 228, S505-S510. [CrossRef]

56. Jeong, Y.-H.; Choe, H.-C. AC impedance behaviors of electrochemically deposited Si-hydroxyapatite films on nanotube-formed Ti-Nb-Zr alloys. J. Nanosci. Nanotechnol. 2014, 14, 9014-9029. [CrossRef]

57. Turdean, G.L.; Craciun, A.; Popa, D.; Constantiniuc, M. Study of electrochemical corrosion of biocompatible Co-Cr and Ni-Cr dental alloys in artificial saliva. Influence of $\mathrm{pH}$ of the solution. Mater. Chem. Phys. 2019, 233, 390-398. [CrossRef]

58. Souto, R.M.; Laz, M.M.; Reis, R.L. Degradation characteristics of hydroxyapatite coatings on orthopaedic TiAlV in simulated physiological media investigated by electrochemical impedance spectroscopy. Biomaterials 2003, 24, 4213-4221. [CrossRef]

59. Ngo, T.T.H.; Fort, I.C.; Pham, T.H.; Turdean, G.L. Ordered Mesoporous Silica Incorporating Platinum Nanoparticles as Electrode Material for Paracetamol Detection. Electroanalytics 2021, 33, 323-335.

60. Pan, J.; Thierry, D.; Leygraf, C. Electrochemical impedance spectroscopy study of the passive oxide film on titanium for implant application. Electrochim. Acta 1996, 41, 1143-1153. [CrossRef]

61. Shanaghi, A.; Mehrjou, B.; Ahmadian, Z.; Souri, A.R.; Chu, P.K. Enhanced corrosion resistance, antibacterial properties, and biocompatibility by hierarchical hydroxyapatite/ciprofloxacin-calcium phosphate coating on nitrided NiTi alloy. Mater. Sci. Eng. C 2021, 118, 111524. [CrossRef] 